\title{
Secretory expression of K88 (F4) fimbrial adhesin FaeG by recombinant Lactococcus lactis for oral vaccination and its protective immune response in mice
}

\author{
Chun Xia Hu $\cdot$ Zi Rong Xu · Wei Fen Li . \\ Dong Niu $\cdot$ Ping Lu $\cdot$ Ling Lin Fu
}

Published online: 20 June 2009

(C) Springer Science+Business Media B.V. 2009

\section{Erratum to: Biotechnol Lett (2009) 31:991-997 \\ DOI 10.1007/s10529-009-9966-8}

Unfortunately one of the co-author's first name and last name had been wrongly published. The correct version is Dong Niu and not Niu Dong as published.

The online version of the original article can be found under doi:10.1007/s10529-009-9966-8.

C. X. Hu · Z. R. Xu · W. F. Li ( $₫)$ - D. Niu - L. L. Fu

Key Laboratory of Molecular Animal Nutrition of Ministry of Education, College of Animal Sciences, Zhejiang University, Hangzhou, Zhejiang 310029, People's Republic of China

e-mail: wfli@zju.edu.cn

C. X. Hu

Department of Life Science, Yuanpei College,

Shaoxing University, Shaoxing, Zhejiang 312000,

People's Republic of China

P. Lu

Institute of Microbiology, College of Life Sciences,

Zhejiang University, Hangzhou, Zhejiang 310029,

People's Republic of China 